\title{
Investigation on the Effects of Prefabricated Crack and Strain Rate on Uniaxial Compressive Properties of Frozen Silty Soil
}

\author{
Dongdong Ma $\mathbb{D}^{1,2,3}$ Ezra Esanju Kaunda, ${ }^{2,3}$ and Kun Huang ${ }^{1,2,3}$ \\ ${ }^{1}$ State Key Laboratory of Mining Response and Disaster Prevention and Control in Deep Coal Mine, \\ Anhui University of Science and Technology, Huainan 232001, Anhui, China \\ ${ }^{2}$ Research Center of Mine Underground Engineering, Ministry of Education, Anhui University of Science and Technology, \\ Huainan 232001, Anhui, China \\ ${ }^{3}$ School of Civil Engineering and Architecture, Anhui University of Science and Technology, Huainan 232001, Anhui, China \\ Correspondence should be addressed to Dongdong Ma; dongdonm@126.com
}

Received 1 May 2020; Revised 2 June 2020; Accepted 8 June 2020; Published 30 June 2020

Academic Editor: Yanjun Shen

Copyright ( 2020 Dongdong Ma et al. This is an open access article distributed under the Creative Commons Attribution License, which permits unrestricted use, distribution, and reproduction in any medium, provided the original work is properly cited.

To investigate the uniaxial compressive strength and deformation properties of frozen silty soil with prefabricated crack under various strain rates, the static uniaxial compressive tests were conducted for frozen silty soil using three kinds of binder materials to select the suitable prefabricated crack manufacturing method. Afterward, the static and dynamic stress-strain curves of frozen silty soil with different prefabricated crack numbers were obtained based on static and splitting Hopkinson pressure bar (SHPB) tests. In addition, the high-speed camera was employed to record the fracturing process of frozen silty soil under impact loads. Results indicated that the frozen silty soil specimens with no binder showed higher static strength compared with other two binder materials (plaster and Vaseline). The strength growth rate of frozen silty soil showed threestage (fast-slow-rapid) change characteristics. The peak strain of frozen silty soil under static loads scope was higher compared with that under dynamic loads, while its dynamic peak strain with various prefabricated crack numbers was remarkably ratedependent. The absorbed energy density of frozen silty soil was subject to a negative (positive) relationship with the prefabricated crack numbers (strain rate). The dominated crack of intact frozen silty soil specimen finally presented Y-shaped shear failure. However, tensile cracks parallel to stress wave propagation direction were observed for the frozen silty soil specimen with prefabricated crack.

\section{Introduction}

Frozen soil is a typical four-phase composite material (i.e., rock or soil particles, air particles, liquid water, and ice particles) [1-3]. The mechanical properties of frozen soil were more complex compared to ordinary soil due to the ice particles, which showed high sensitivity to temperature change in surrounding environment $[4,5]$. Seasonal frozen soil covered about 53.5\% of China's land area [6]. Quick development rate in the fields of technology and engineering in previous years led to a gradual increase in the number of construction projects in cold regions, such as tunnels, highways, pipelines, and railways [7-11]. In addition, during the design, construction, and service periods of frozen soil structures, the frozen soil was subjected to different external loads in a vast range of strain rate [12-15].

Generally, research studies on physical and mechanical properties of frozen soil responses to multiple strain rates (static, quasi-static, and dynamic) had been systematically studied $[16,17]$. For ensuring the ultimate bearing capacity of frozen gravelly soil under static loading range, the static uniaxial compression tests were conducted with the strain rate ranging from $10^{-5}$ to $10^{-3}$, and test results indicated that the uniaxial compression strength of frozen gravelly soil increased linearly with increasing strain rate under various freezing temperatures [18]. In addition to static properties, comprehending the dynamic behavior of frozen soil could help improve the excavation efficient and stability of frozen 
soil engineering in cold regions subjected to drilling, blasting, and earthquake effects $[19,20]$. Hence, there were a growing number of efforts devoted to better understand the strength and deformation behavior of frozen soil subjected to dynamic loads based on the splitting Hopkinson pressure bar (SHPB) [14, 21, 22], which had been considered an invaluable and effective device providing dynamic loading on various materials [23-25], and test results demonstrated that the strain rate and dynamic peak stress could be viewed as a positive linear relationship when the freezing temperature value was determined [14], which illustrated the dynamic compressive strength of frozen soil materials was remarkably rate-dependent. Zhang et al. [21] obtained the dynamic stress-strain relationship and failure modes of frozen soil with various strain rates, and an improved ZWT constitutive model was established to describe its damage mechanism and strain rate effect. Fu et al. [22] found that the strain rate showed positive effect on both peak stress and final strain of frozen soil under impact loads.

Investigations on effects of preexisting cracks on the mechanical properties of rocks, concrete, and other materials had been analytically and numerically conducted [26-35]. Experiment and numerical simulation results revealed that the stress wave propagation, the strength and deformation properties, and failure mode of materials were affected by the number, distribution, and angle of preexisting cracks. Wang et al. [26] found that the uniaxial compression peak stress of intact granite specimen was 3.2 times larger than the specimens with flaws inclination angle of 0 ; moreover, both the strength and failure mode of granite were affected by inclination angle. To investigate the stress wave propagation and fracturing mechanism of rock with various angles subjected to dynamic stress wave, Li et al. [27] carried out SHPB tests on red sandstone with four joint angles (i.e., $0^{\circ}, 15^{\circ}, 30^{\circ}$, and $45^{\circ}$ ) and captured its complete fracturing process by high-speed camera. Bai et al. [28] investigated the physical and mechanical behavior of frozen rock materials with two prefabricated fissures under different freezing temperatures at a constant dip angle, and results showed both the elastic modulus and peak strength of red sandstone specimen increased as a result of confining pressure.

It was well known that cracks generally existed during the formation of frozen soil; in addition, cracks were generated during the design, construction, and operation periods for frozen soil engineering $[36,37]$. Thus, it was necessary to conduct research on the effect of crack on the mechanical behavior and failure process of frozen soil. However, previous works mainly concentrated on the mechanical properties of intact frozen soil response to static or dynamic loads. In this research, the WDT-100 pattern pressure test system and SHPB devices were used to investigate the effects of prefabricated crack number and strain rate on the stress-strain curves, strength, peak strain, and absorbed energy density of frozen silty soil. In addition, the dynamic crack initiation, propagation, expansion, and connection process of frozen silty soil specimen with various prefabricated cracks was obtained based on high-speed camera. Test results could help improve the excavation and crushing efficiency and evaluate the safety and stability in frozen soil engineering.

\section{Preparation of Frozen Soil with Prefabricated Crack and Test Device}

2.1. Preparation of Frozen Soil with Prefabricated Crack. The test frozen soil was obtained from deep foundation engineering in Huainan, Anhui province. The basis physical parameters of disturbed soil are described in Table 1.

The preparation method of frozen soil with prefabricated crack was described as follows. The soil was firstly dried for about more than 24 hours at a temperature of about $105^{\circ} \mathrm{C}$ in an electric dry oven, later crushed and sieved to a size less than $2 \mathrm{~mm}$, and then stored in plastic bags to prevent the loss of moisture. The water content of frozen silty soil in this study was $24.2 \%$. Each specimen prepared for static and dynamic loading had dimensions of $\Phi 50 \mathrm{~mm} \times 100 \mathrm{~mm}$ and $\Phi 50 \mathrm{~mm} \times 50 \mathrm{~mm}$ [6], respectively. The soil was prepared with different binders (i.e., gypsum, Vaseline, and no binder) with one prefabricated crack; after determining the suitable binder materials, we prepared frozen silty soil specimens with different number of prefabricated cracks at an angle of zero degrees; taking dynamic specimen as an example, the prefabricated crack production method was as follows: a half specimen $(\Phi 50 \mathrm{~mm} \times 25 \mathrm{~mm})$ and a quarter specimen $(\Phi$ $50 \mathrm{~mm} \times 12.5 \mathrm{~mm}$ ) were made using suitable corresponding moulds, and then two half specimens were placed together to make specimen with one prefabricated crack, while one half specimen and two quarter specimens were used for preparing specimen with two prefabricated cracks, and four quarter specimens were used for specimen with three prefabricated cracks. The soil specimens were later placed in a freezer with $-20^{\circ} \mathrm{C}$ for more than 24 hours and then changed to the desired freeing temperature of $-10^{\circ} \mathrm{C}$. The prepared frozen silty soil specimens for static loads with different binder materials and prefabricated crack numbers are shown in Figure 1. The frozen silty soil specimens for dynamic tests with various prefabricated crack numbers are shown in Figure 2.

2.2. Static and Dynamic Test Devices. WDT-100 pattern pressure test system was carried out to obtain the static mechanical properties of frozen silty soil, while SHPB system was employed for dynamic test, as shown in Figure 3.

The static WDT-100 pattern pressure test system contained low temperature control box, data acquisition system, upper dowel bar, and lower bearing platform. The frozen silty soil specimen was placed between the upper dowel bar and lower bearing platform; meanwhile, two displacement meters were arranged on the two sides of specimen to accurately collect its average deformation data. Under static loads, the static strength and deformation properties of frozen silty soil specimen were tested with four strain rates $\left(0.01 \mathrm{~s}^{-1}, 0.02 \mathrm{~s}^{-1}, 0.04 \mathrm{~s}^{-1}\right.$, and $\left.0.08 \mathrm{~s}^{-1}\right)$. The dynamic compression test was achieved using the SHPB system with different air pressures (0.3 MPa, 0.4 MPa, 0.5 MPa, 0.6 MPa, $0.7 \mathrm{MPa}$, and $0.8 \mathrm{MPa}$ ). The purpose of SHPB system was to 
TABLE 1: The basis physical parameters of disturbed soil.

\begin{tabular}{lc}
\hline Properties & Values \\
\hline Liquid limit $(\%)$ & 22.5 \\
Plastic limit (\%) & 32.2 \\
Plasticity index & 9.7 \\
Water content $(\%)$ & 24.2 \\
$(1 \mathrm{~mm}<$ diameter $<2 \mathrm{~mm})$ & $9.7 \%$ \\
$(0.5 \mathrm{~mm}<$ diameter $<1 \mathrm{~mm})$ & $11.5 \%$ \\
$(0.25 \mathrm{~mm}<$ diameter $<0.5 \mathrm{~mm})$ & $14.1 \%$ \\
$(0.075 \mathrm{~mm}<$ diameter $<0.25 \mathrm{~mm})$ & $12.4 \%$ \\
$($ Diameter $<0.075 \mathrm{~mm})$ & $52.3 \%$ \\
Soil classification-GB 50021 (Chinese Standard) & Silty \\
\hline
\end{tabular}

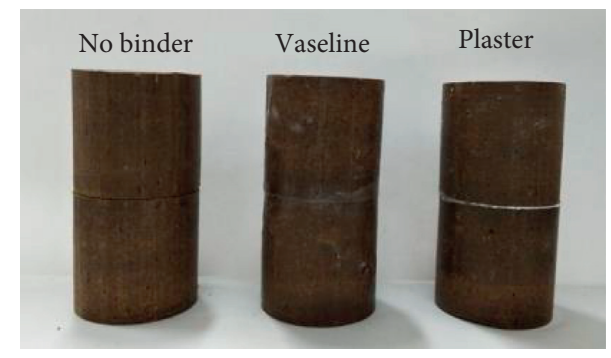

(a)

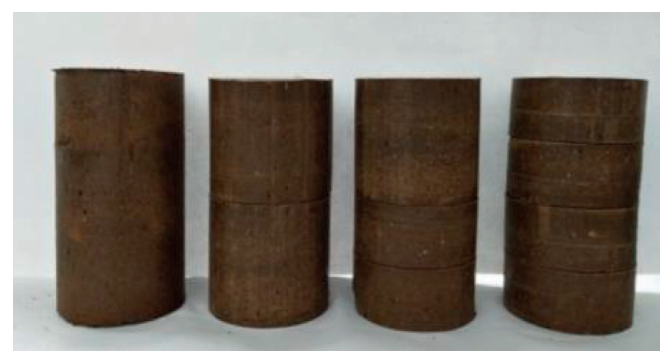

(b)

FIGURE 1: Frozen silty soil specimens for static tests. (a) With different binders. (b) With different prefabricated crack numbers.

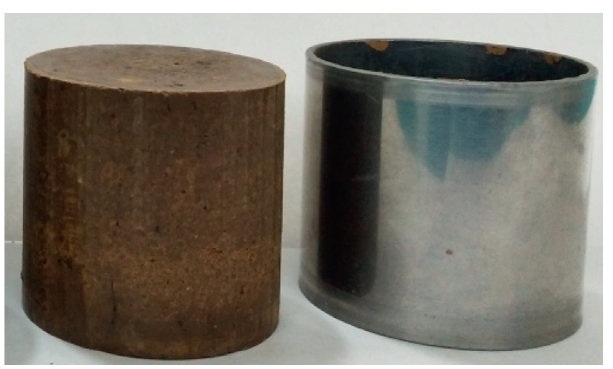

(a)

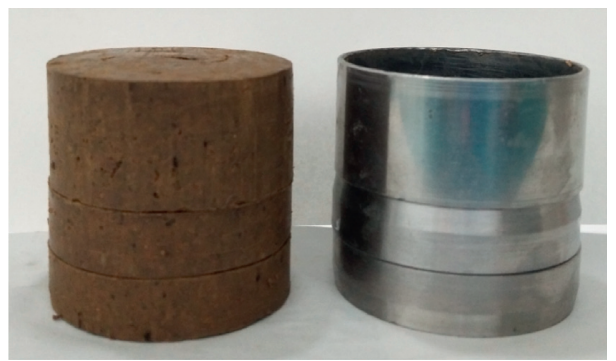

(c)

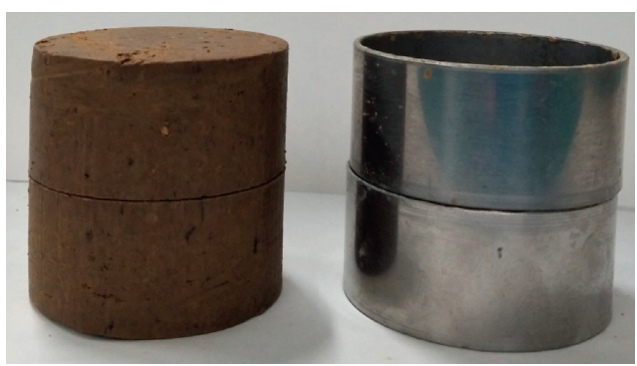

(b)

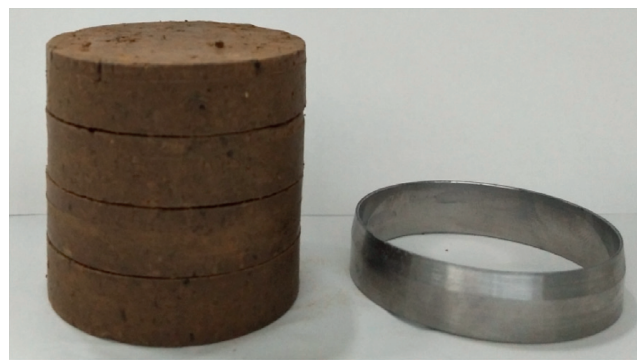

(d)

FIGURE 2: Frozen silty soil specimens for dynamic tests with various prefabricated crack numbers.

apply impact pressure to frozen silty soil specimen placed between incident and transmitted bars and determine its dynamic behavior within a larger strain rate range. In this test, Memrecam HX-3 high-speed camera produced by NAC Image Technology Company coupled with a ring-shaped flash light was used to record the fracturing process of frozen silty soil with prefabricated crack under dynamic loads. In addition, a temperature control box was adopted to reduce the temperature changes of frozen silty soil during impact process. After collecting the incident, reflected, and transmitted signals obtained from resistance and semiconductor strain gauges, the dynamic compressive stress $\sigma(t)$, strain $\varepsilon(t)$, and strain rate $\dot{\varepsilon}(t)$ could be calculated as follows $[21,22]$ : 


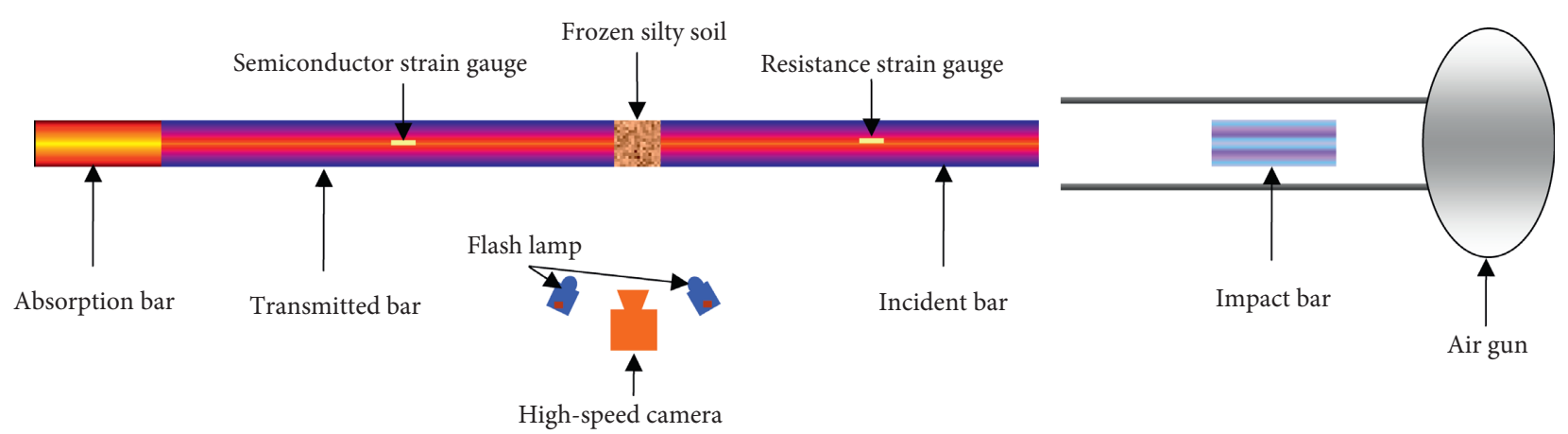

Figure 3: SHPB test system.

$$
\begin{aligned}
\sigma(t) & =\frac{E_{0} A_{0}}{A_{s}} \varepsilon_{\mathrm{T}}(t), \\
\mathcal{E}(t) & =\frac{C_{0}}{l_{s}} \int_{0}^{\tau}\left[\varepsilon_{\mathrm{I}}(t)-\varepsilon_{\mathrm{R}}(t)-\varepsilon_{\mathrm{T}}(t)\right] \mathrm{d} t, \\
\dot{\varepsilon}(t) & =\frac{C_{0}}{l_{s}}\left[\varepsilon_{\mathrm{I}}(t)-\varepsilon_{\mathrm{R}}(t)-\varepsilon_{\mathrm{T}}(t)\right],
\end{aligned}
$$

where $E_{0}, A_{0}, C_{0}, A_{\mathrm{s}}, l_{\mathrm{s}}$ are Young's modulus, the crosssectional area, the elastic wave speed of the bar, and the cross-sectional area and height of frozen silty soil specimen, respectively; $\varepsilon_{\mathrm{I}}(t), \varepsilon_{\mathrm{R}}(t)$, and $\varepsilon_{\mathrm{T}}(t)$ are the incident strain, reflected strain, and transmitted strain, respectively; and $t$ is the duration time of elastic wave.

Previous investigation indicated that the absorbed energy density $(W)$ could reflect the energy dissipation characteristic of frozen soil under impact loading [38], which could be calculated by

$$
W=\frac{W_{\mathrm{s}}(t)}{V_{\mathrm{s}} W_{\mathrm{I}}(t)},
$$

where $W_{\mathrm{S}}(t)$ and $W_{\mathrm{I}}(t)$ are the absorbed energy of frozen silty soil specimen and incident energy, respectively, and $V_{\mathrm{s}}$ is the volume of frozen silty soil specimen.

\section{Selection of Suitable Binder Materials}

In this test, the static strength of frozen silty soil with three kinds of binder materials was compared and is shown in Figure 4 . It could be noticed that strain rate strengthening effect was observed for frozen silty soil specimens with various binder materials. However, the increase rate was significantly different for various binder materials; for example, when the strain rate increased from $0.01 \mathrm{~s}^{-1}$ to $0.08 \mathrm{~s}^{-1}$, the average compressive strength of frozen silty soil specimen with no binder increased from 2.63 MPa to $3.37 \mathrm{MPa}$, with a larger-scale increase of $28.14 \%$, while the increase degree was $23.6 \%$ for the specimen using Vaseline as the binder under the same condition. The strength of frozen silty soil specimens with various binder materials was much smaller than that with no crack. In addition, under the same strain rate, the frozen silty soil specimens with no binder showed higher strength compared with other two binder materials.

The static failure modes of frozen silty soil using three binder materials are shown in Figure 5. Figure 5(a) illustrates

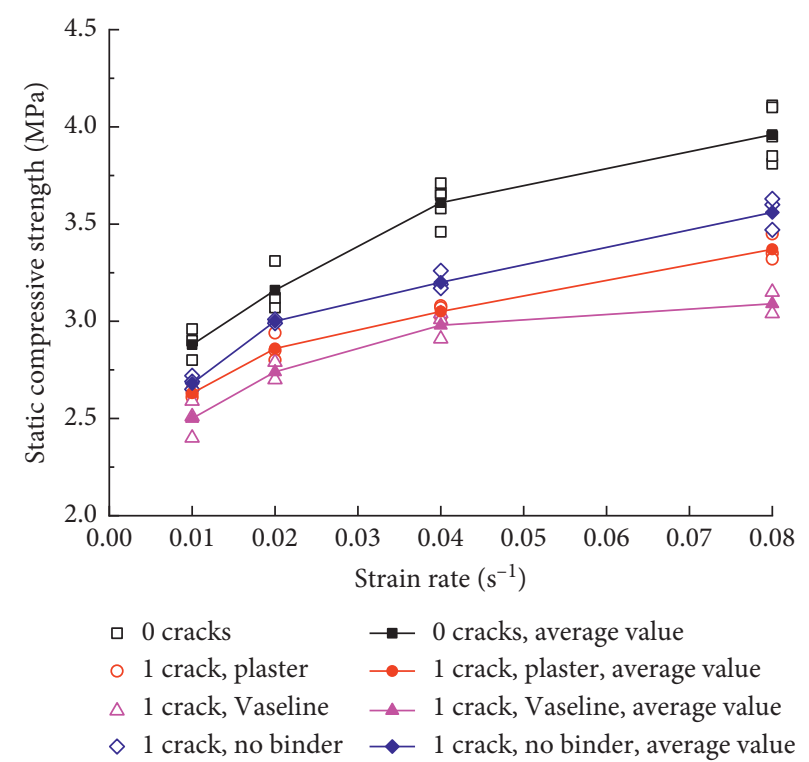

FIgURE 4: Static strength with three kinds of binder materials.

that, for frozen silty soil specimen with no crack, the failure mode was bulge in the middle, which was consistent with test results of previous investigation [36]. For specimen with no binder, small cracks were found near the weakness plane, as shown in Figure 5(b). Additionally, bottom crush and bulge in bottom failure modes were observed using plaster and Vaseline as the binder materials, respectively.

From the above strength and failure mode results, it could be noticed that the group with no binder showed highest strength compared with other two materials; in addition, the failure modes using plaster or Vaseline showed no obvious weak surface characteristics. Moreover, the crack generated in nature was in good agreement with the group with no binder. Hence, no binder method was selected in this research.

\section{Test Results of Frozen Silty Soil with Prefabricated Crack under Various Strain Rates}

4.1. Stress-Strain Curves. The obtained stress-strain curves of frozen silty soil with various prefabricated crack numbers and strain rates are shown in Figure 6. Figure 6 reveals the 


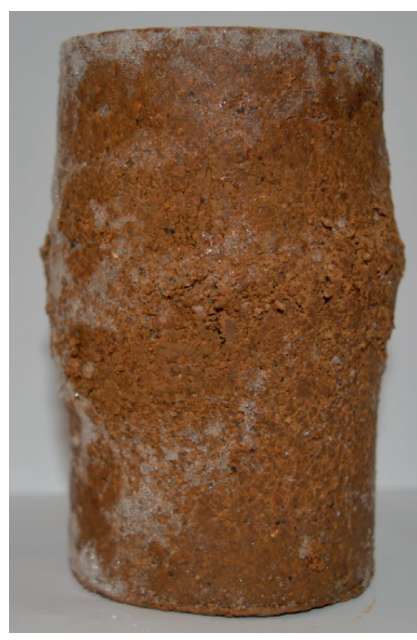

(a)

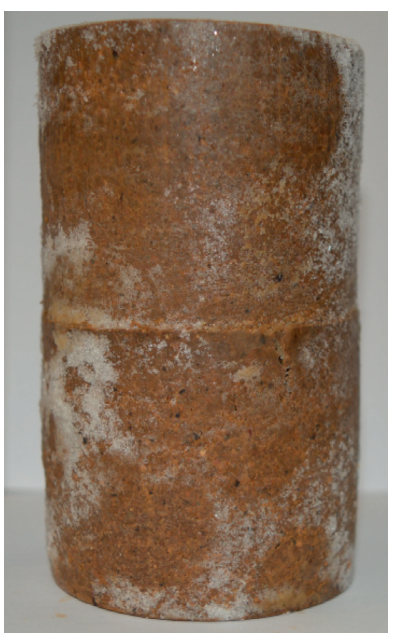

(b)

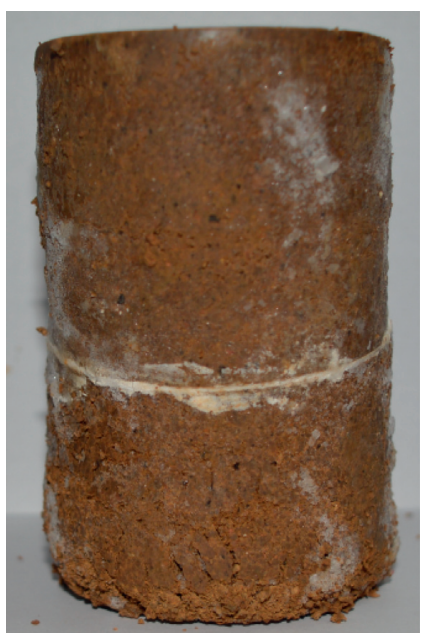

(c)

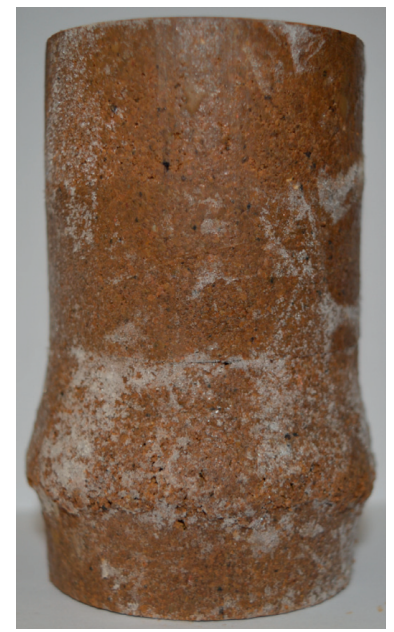

(d)

FIGURE 5: Static failure modes of frozen silty soil using three kinds of binder materials. (a) 0 cracks at $0.01 \mathrm{~s}^{-1}$. (b) $1 \mathrm{crack}$ with no binder at $0.01 \mathrm{~s}^{-1}$. (c) 1 crack using plaster at $0.01 \mathrm{~s}^{-1}$. (d) 1 crack using Vaseline at $0.01 \mathrm{~s}^{-1}$.

following: (1) four-stage characteristics (i.e., compression, elastic, hardening, and softening stages) were observed under static loads for different prefabricated crack numbers; however, obvious compression stage was not found for frozen silty soil under dynamic loads, and the failure stage under dynamic loads was apparent compared with that under static loads. (2) The deformation modulus of frozen silty soil, which was treated as the increase rate of elastic stage, increased with the increase of strain rate under static loads scope, while its values changed within a small range under dynamic loads. (3) Under static loading, the curves also clearly showed that slowly decreasing speed was observed after reaching peak stress, reflecting plastic failure characteristic, while under dynamic loading the abrupt decrease in softening stages was found, showing brittle failure characteristic.

4.2. Strength and Peak Strain. The strength and its corresponding strain could reflect the ability of frozen silty soil specimen to resist external static and dynamic loads. In the present research, the strength of frozen silty soil with various prefabricated crack numbers within a larger strain rate range was obtained and is shown in Figure 7.

Figure 7 illustrates that the prefabricated crack number had a notable effect on the strength performance of frozen silty soil specimens. Moreover, "fast-slow-rapid" three-stage characteristics were observed for the strength growth rate of frozen silty soil based on the static and dynamic experiments; specifically, when the strain rate increased from $0.01 \mathrm{~s}^{-1}$ to $0.08 \mathrm{~s}^{-1}$, the first stage had a fast compressive strength increment, and then a gradual slow strength increment was found for the second stage. Finally, a regular remarkable rapid increment rate of dynamic compressive strength of frozen silty soil was found, which was considered as the third stage. For example, the static strength of frozen silty soil specimen increased from $2.68 \mathrm{MPa}\left(0.01 \mathrm{~s}^{-1}\right)$ to $3.56 \mathrm{MPa}\left(0.08 \mathrm{~s}^{-1}\right)$ for one prefabricated crack, with an increment of $0.88 \mathrm{MPa}$; as a contrast, a rise of $1.84 \mathrm{MPa}$ was obtained when the strain rate increased from $134 \mathrm{~s}^{-1}$ to $266 \mathrm{~s}^{-1}$.

Figure 8 demonstrates the peak strain of frozen silty soil with various prefabricated crack numbers and strain rates. It could be clearly noticed that the peak strain of frozen silty soil under static loads scope was significantly higher compared with that under dynamic loads, and this phenomenon indicated that the deformation of frozen silty soil specimen under static loads to reach the failure state was greater than that under dynamic loads. This result from the above analysis was consistent with a previous theory [6]. Under static loads, when the strain rate increased from $0.01 \mathrm{~s}^{-1}$ to $0.08 \mathrm{~s}^{-1}$, there was no obvious change rule for peak strain, which varied from 0.085 to 0.146 . As a contrast, the dynamic peak strain of frozen silty soil with various prefabricated crack numbers was remarkably rate-dependent, and it linearly increased with the increase of strain rate. Moreover, the effect of prefabricated crack numbers on peak strain was not obvious.

4.3. Prefabricated Crack Degradation Effect. The degradation coefficient $(\zeta)$ was defined to describe the strength reduction degree caused by prefabricated cracks, which was expressed as follows:

$$
\zeta=\frac{\sigma_{0}-\sigma_{n}}{\sigma_{0}} \times 100 \%
$$

where $\sigma_{0}$ is the strength of frozen silty soil with no prefabricated crack and $\sigma_{n}$ is the strength of frozen silty soil with prefabricated cracks (i.e., 1, 2, and 3).

The calculated average value of degradation coefficient with different prefabricated cracks and strain rates is shown in Figure 9. Under dynamic loads, the degradation coefficient of frozen silty soil decreased with increasing strain rate. Furthermore, the prefabricated cracks affected the performance of frozen silty soil as the strength 


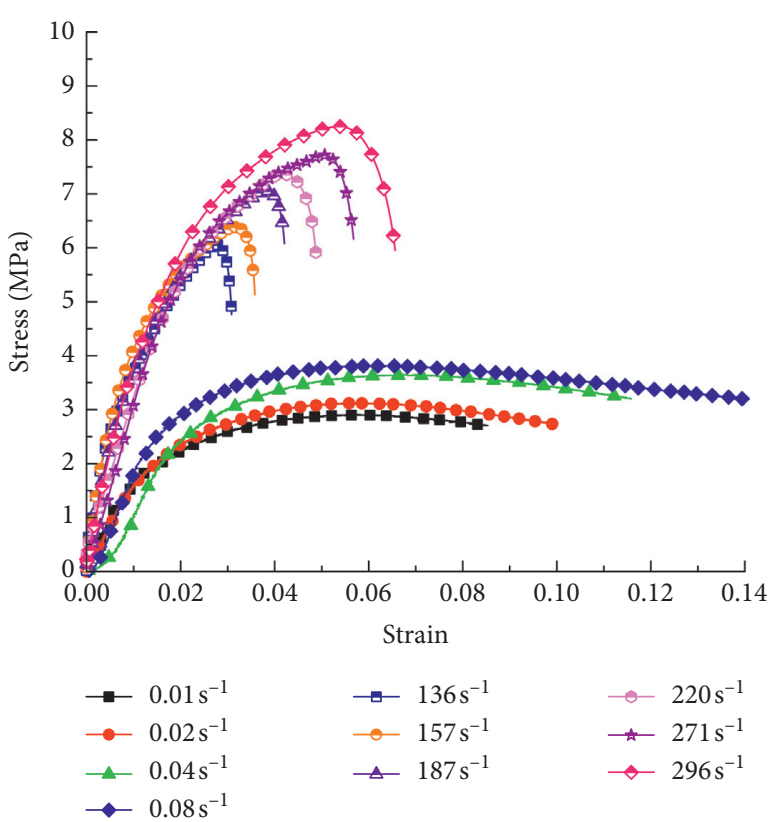

(a)

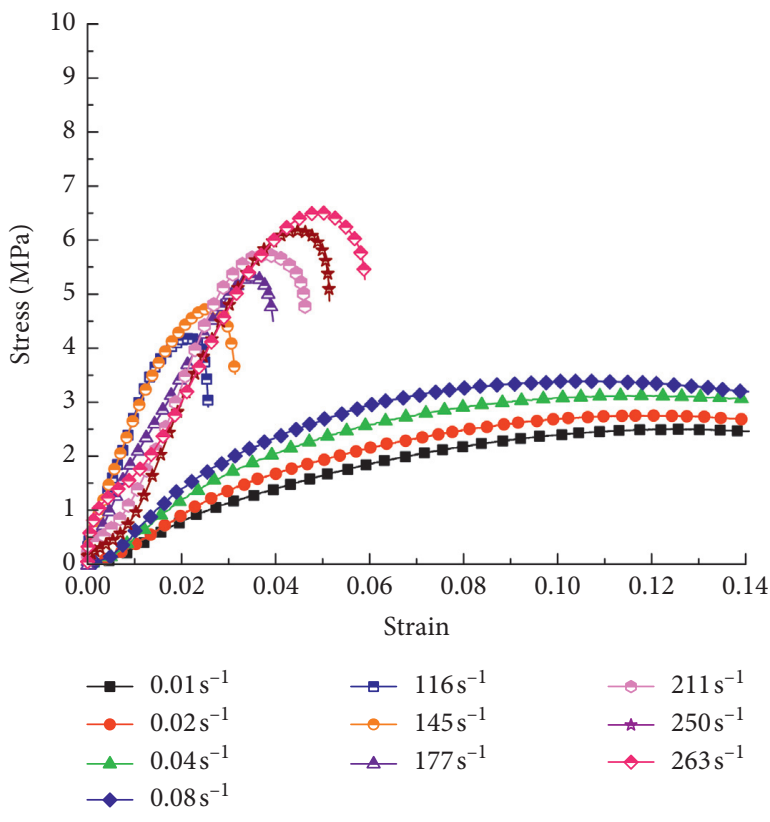

(c)

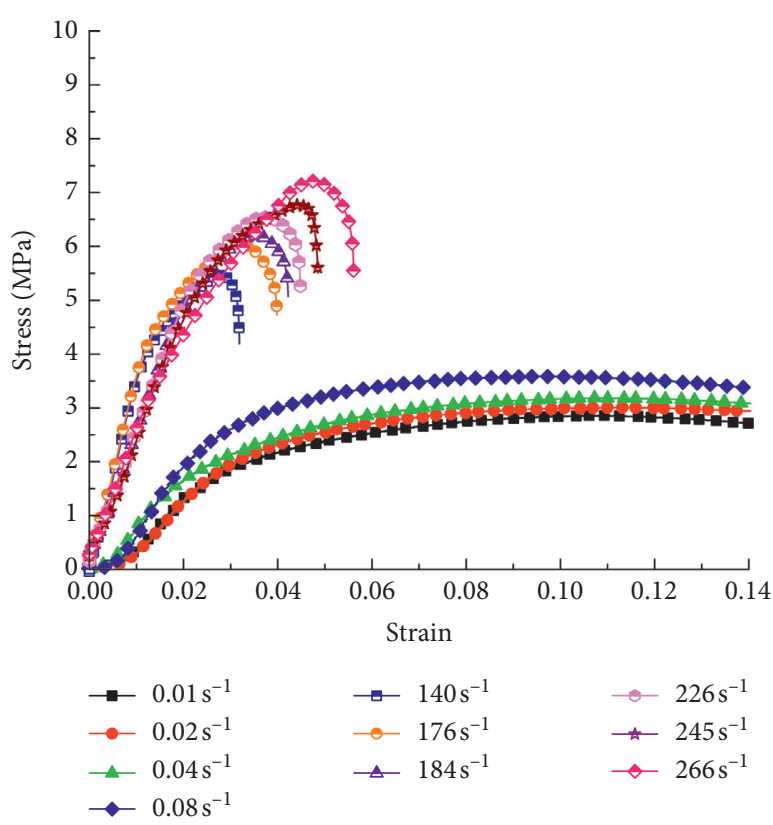

(b)

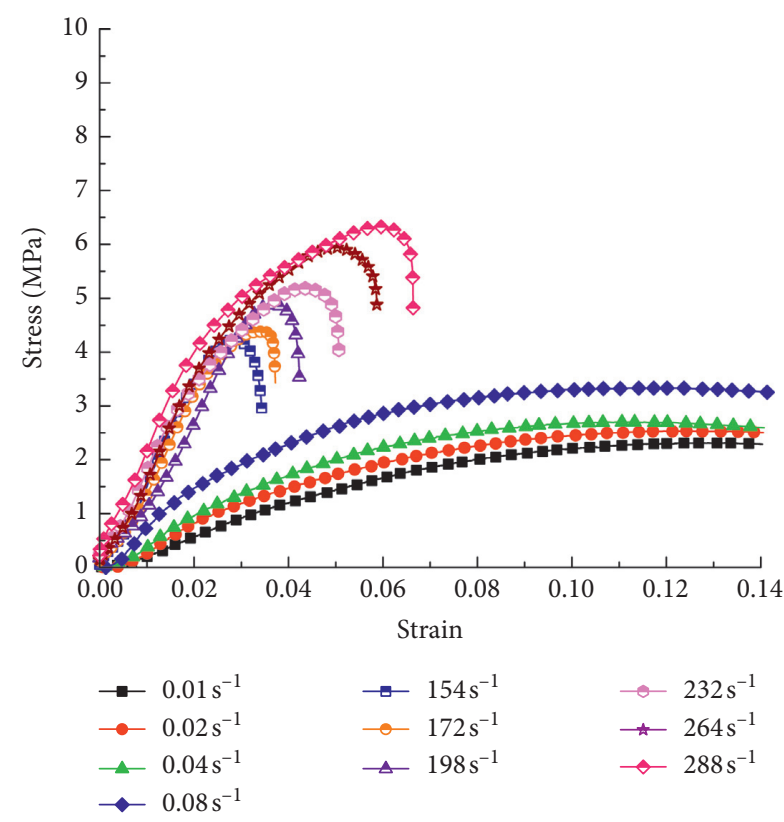

(d)

FIGURE 6: Stress-strain curves of frozen silty soil with various prefabricated crack numbers and strain rates. (a) 0 prefabricated cracks. (b) 1 prefabricated crack. (c) 2 prefabricated cracks. (d) 3 prefabricated cracks.

reduced due to the increase in the number of cracks, and the prefabricated cracks reduced the strength from 5\% to $35 \%$ compared with the intact frozen silty soil specimen. Under $0.04 \mathrm{~s}^{-1}$ strain rate, the average value of degradation coefficient with three prefabricated cracks was $27 \%$, which was higher than the values of $11 \%$ and $17 \%$ with one or two cracks. For frozen silty soil with three prefabricated cracks, the largest degradation coefficient under static and dynamic loads could reach $27 \%$ and $35 \%$ respectively.
4.4. Absorbed Energy Density. According to the calculation method of formula (2), the variation in absorbed energy density of frozen silty soil with strain rates under various prefabricated crack numbers was obtained and is shown in Figure 10.

It could be seen that, under the same strain rate, the absorbed energy density of frozen silty soil was subject to a negative relationship with the prefabricated crack numbers. This phenomenon demonstrated that prefabricated crack weakened the energy absorption efficiency of frozen silty soil and the specimens with more prefabricated crack numbers 


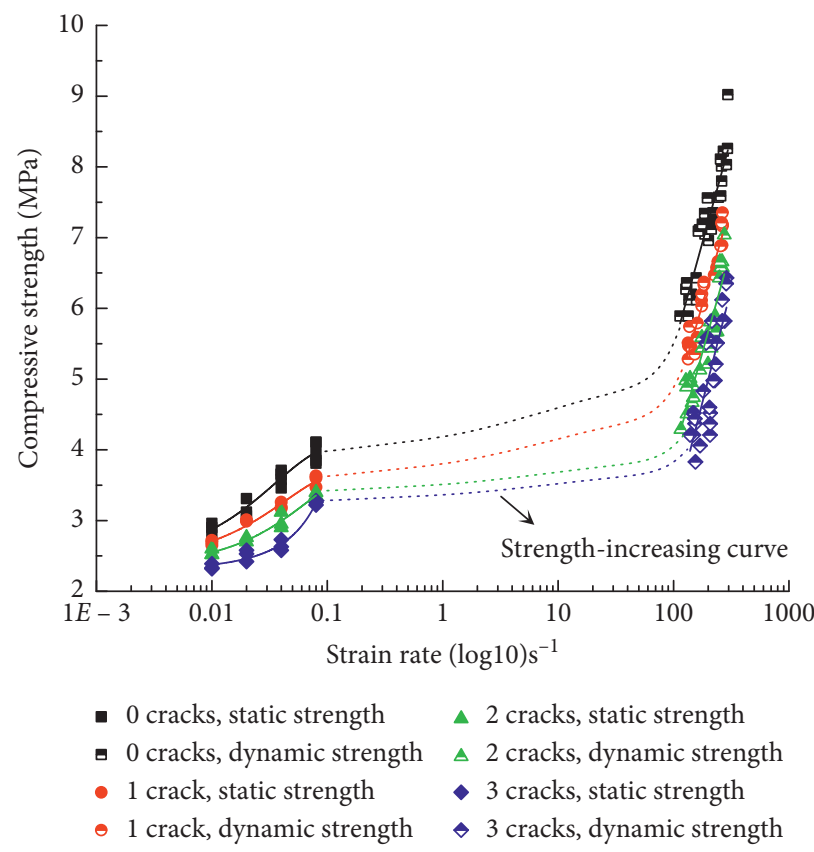

Figure 7: Static and dynamic strengths of frozen silty soil with various prefabricated crack numbers.

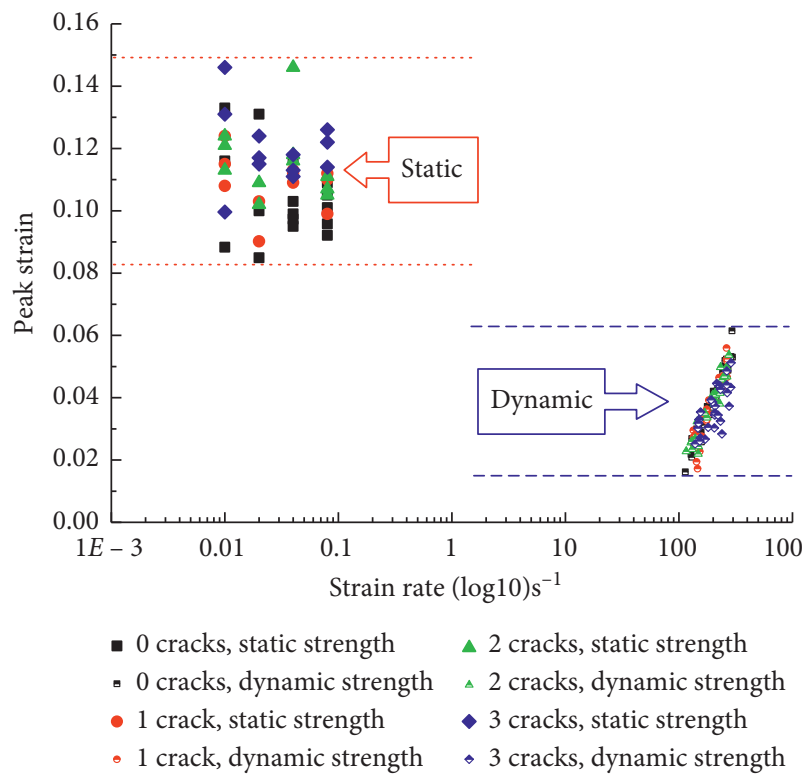

Figure 8: Peak strain of frozen silty soil with various prefabricated crack numbers and strain rates.

need less energy for reaching the failure stage. Moreover, with the increase of strain rate, the value of absorbed energy density of frozen silty soil increased linearly, and this was attributed to the increase in number and expansion of cracks caused by larger strain rate [6]. The relationship between strain rate and absorbed energy density could be expressed as a quadratic function:

$$
W=a(\dot{\varepsilon})^{2}+b(\dot{\varepsilon})+c,
$$

where $a, b$, and $c$ are the fitting parameters, and their values with various prefabricated crack numbers are shown in Table 2.
4.5. Failure Mode and Fracturing Process. The crack initiation and propagation were strongly affected by the number of prefabricated cracks under impact stress wave. The fracturing processes of frozen silty soil under dynamic loading were recorded by the high-speed camera, and the ultimate failure modes of intact and prefabricated crack frozen silty soil specimens are listed in Table 3.

It could be noticed that the dominated crack of intact frozen silty soil specimen finally presented Y-shaped shear failure. Moreover, some corners of the specimen collapsed and failed into pieces under loading process, and specimen was destroyed into three pieces. For frozen silty soil 


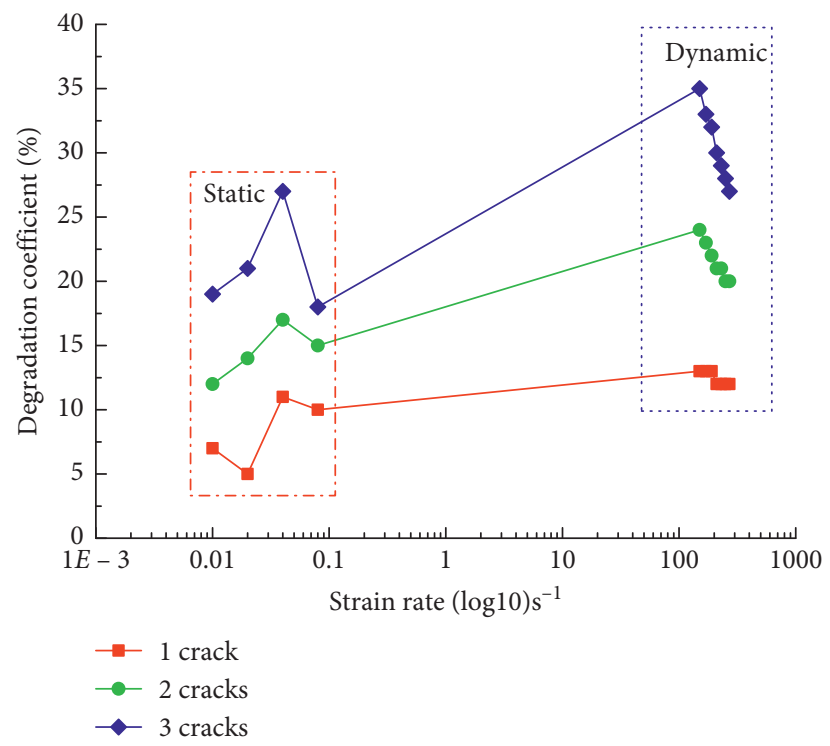

Figure 9: Degradation coefficient with different prefabricated cracks and strain rates.

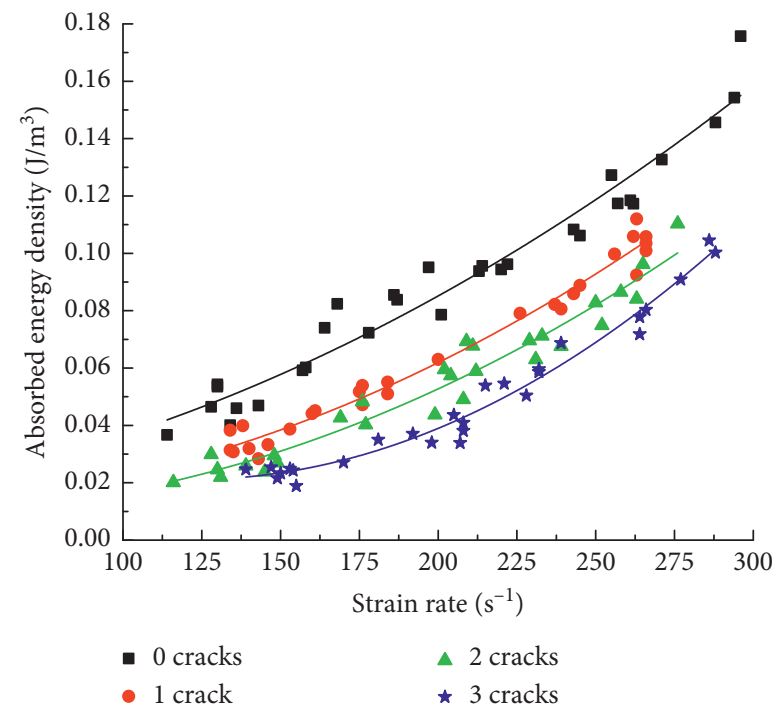

FIGURE 10: Variation in absorbed energy density of frozen silty soil with strain rates.

TABLE 2: The values of fitting parameters $a, b$, and $c$.

\begin{tabular}{|c|c|c|c|c|}
\hline Prefabricated crack number & $a$ & $b$ & $c$ & $R^{2}$ \\
\hline 0 & 0.013 & $1.12 \times 10^{-4}$ & $1.24 \times 10^{-6}$ & 0.95 \\
\hline 1 & 0.012 & $-4.99 \times 10^{-5}$ & $1.48 \times 10^{-6}$ & 0.98 \\
\hline 2 & 0.011 & $-9.22 \times 10^{-5}$ & $1.5 \times 10^{-6}$ & 0.96 \\
\hline 3 & 0.064 & $-7 \times 10^{-5}$ & $2.89 \times 10^{-6}$ & 0.97 \\
\hline
\end{tabular}

specimen with one prefabricated crack, tensile cracks parallel to stress wave propagation direction initiated from the surface between specimen 1-2 and incident bar, and then it propagated to specimen 1-1 and generated an extended crack; meanwhile, some parallel small cracks simultaneously appeared on the two sides of previous dominated crack in specimen 1-2. Finally, the bottom part was destroyed and gradually separated from the frozen silty soil specimen. In terms of the specimens with two and three prefabricated cracks, tensile cracks appeared during fracture process, and the detailed whole fracture processes of them are presented in Figures 11 and 12.

Figure 11 illustrates that volume expansion occurred in specimen $2-1$ at the initial stage of loading, and two primary tensile cracks $\left(T_{1-1}\right.$ and $\left.T_{1-2}\right)$ appeared simultaneously in specimen 2-3. With the increase of dynamic stress, the 
TABLE 3: Ultimate failure mode of intact and prefabricated crack frozen silty soil specimens.

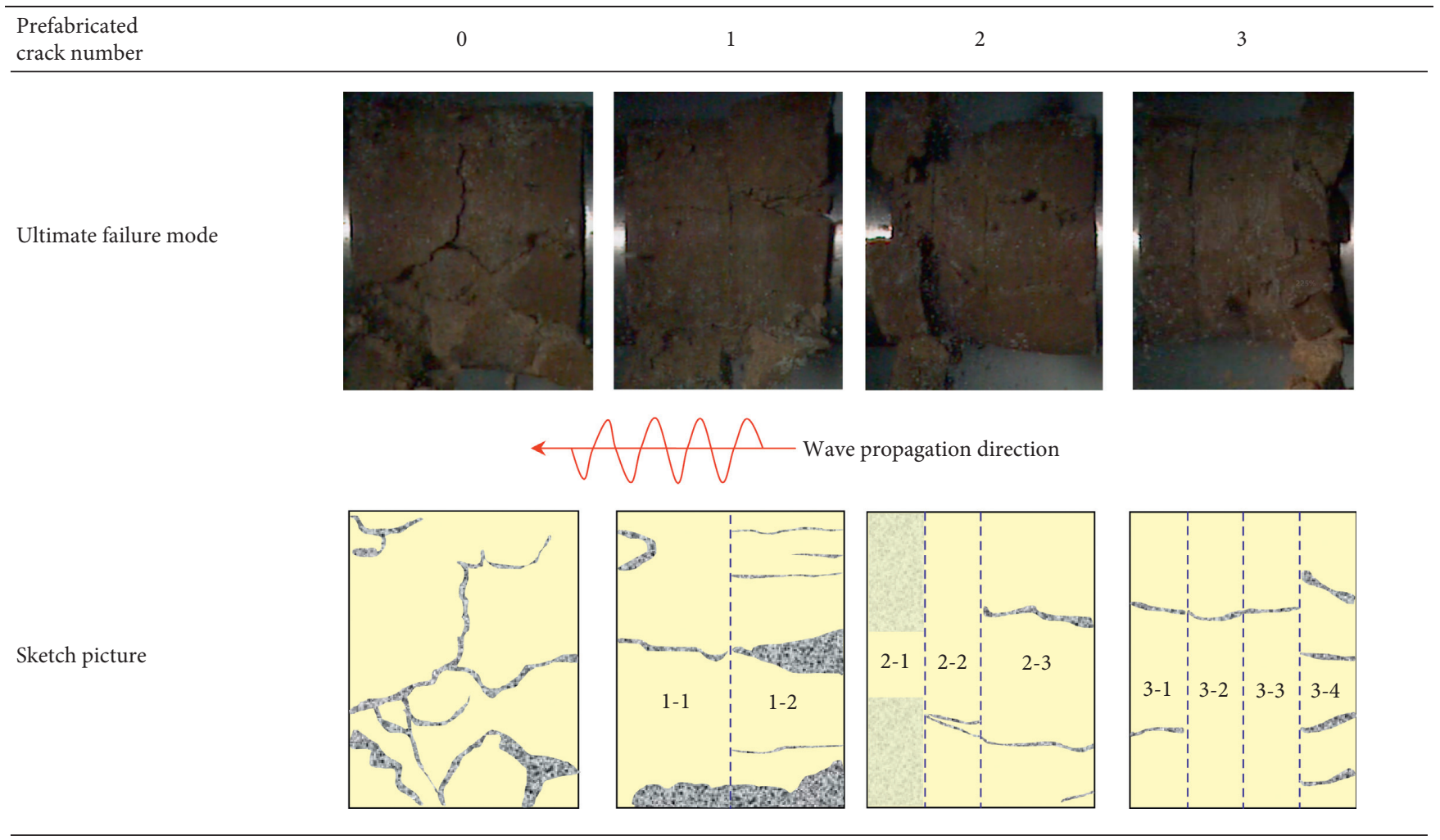
Note
Intact specimen
Prefabricated crack specimen (2-3 represents the third piece for specimen with two prefabricated cracks)

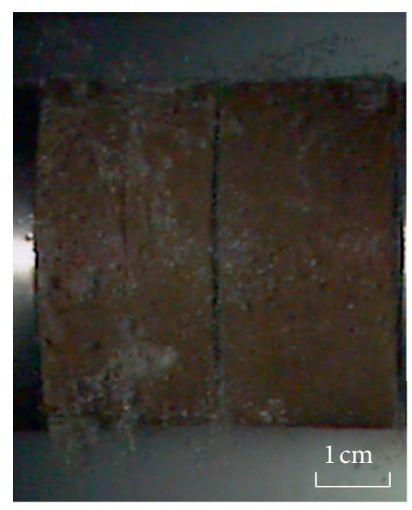

(a)

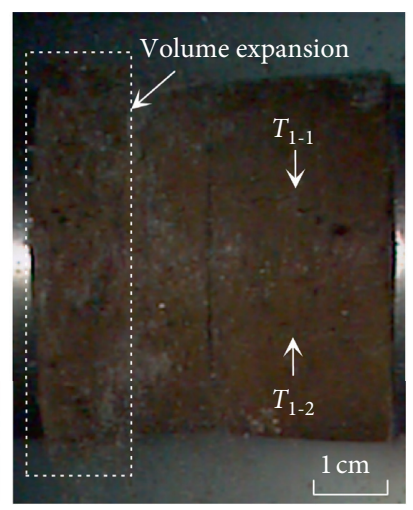

(b)

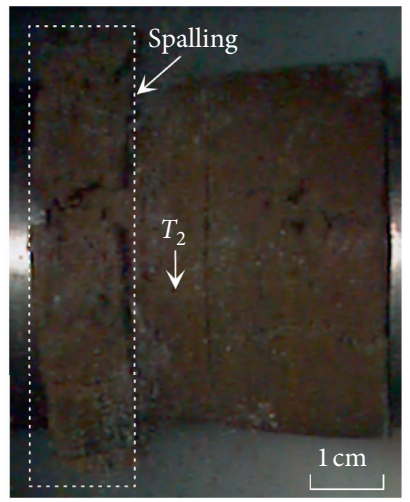

(c)

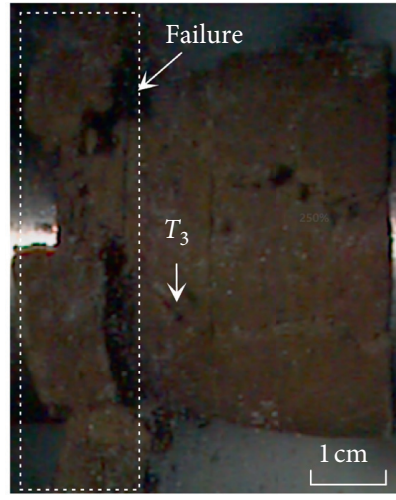

(d)

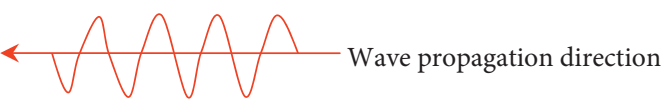

FIGURE 11: Fracture processes of frozen silty soil specimen with two prefabricated cracks.

curved surface of specimen 2-1 spalled from its main part, while new crack $T_{2}$ emerged in specimen 2-2, and the former two cracks ( $T_{1-1}$ and $T_{1-2}$ ) continued expanding. Finally, the curved surface of specimen 2-1 failed and neonatal crack $T_{3}$ appeared and connected with the previous cracks $T_{1-2}$ and $T_{2}$.

The typical fracturing process of frozen silty soil specimen with three prefabricated cracks in response to dynamic stress wave is shown in Figure 12 . Tensile cracks $T_{1-1}, T_{1-2}$, and $T_{1-3}$ emerged simultaneously with the larger deformation in specimen 3-4, and then corner spalling occurred on the surface between specimen 3-1 and transmitted bar caused by the stress concentration and friction on the frozen silty soil surface. Afterward, spalling happened in the surface of specimen 3-1 and the contact area between specimens 3-2 and 3-3. In addition, specimen 3-4 collapsed and failed into pieces under dynamic loads. 


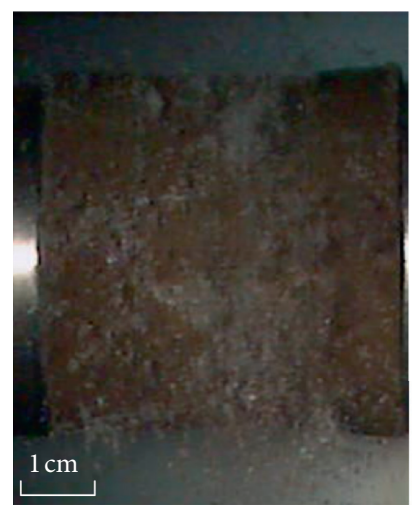

(a)

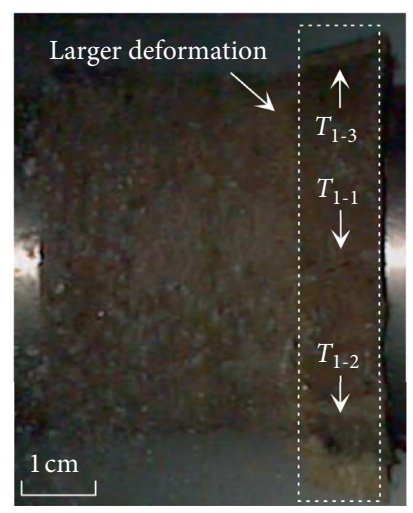

(b)

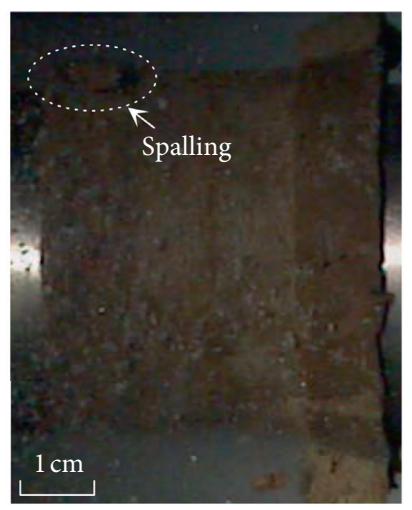

(c)

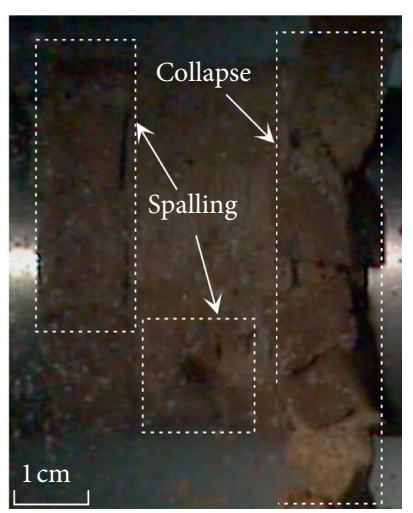

(d)

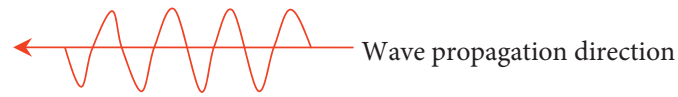

FIGURE 12: Fracture processes of frozen silty soil specimen with three prefabricated cracks.

\section{Conclusions}

(1) The failure modes of frozen silty soil using plaster or Vaseline as the binder materials showed no obvious weak surface characteristics under static loads, and the group with no binder showed highest strength compared with the other two materials. The prefabricated crack number had a notable effect on the strength performance of frozen silty soil specimens. In addition, "fast-slow-rapid" three-stage characteristics were observed for the strength growth rate of frozen silty soil.

(2) Under the same strain rate, the absorbed energy density of frozen silty soil was subject to a negative relationship with the prefabricated crack numbers. The relationship between strain rate and absorbed energy density could be expressed as a quadratic function.

(3) The dominated crack of intact frozen silty soil specimen finally presented Y-shaped shear failure, and some corners of the specimen collapsed and failed into pieces under loading process. However, for frozen silty soil specimen with prefabricated crack, tensile cracks parallel to stress wave propagation direction were observed and finally the failure mode of specimen was determined.

\section{Data Availability}

The datasets generated and analyzed during the current study are available from the corresponding author upon reasonable request.

\section{Conflicts of Interest}

The authors declare that there are no conflicts of interest regarding the publication of this paper.

\section{Acknowledgments}

This work received financial support from Anhui Provincial Natural Science Foundation (no. 1908085QE212), the project funded by China Postdoctoral Science Foundation (no. 2019M652162), and Doctoral Fund Project of Anhui University of Science \& Technology (no. 11695). Thanks are due to Anhui University of Science \& Technology, for providing the static and dynamic test conditions.

\section{References}

[1] D. Zhang, G. Yang, X. Niu, L. Zhang, and Z. Wang, "Study on application effect of sand consolidating agent for slope of highway subgrade in season frozen zone," Advances in Civil Engineering, vol. 2019, Article ID 3716153, 7 pages, 2019.

[2] J. Yu, G. Liu, Y. Cai, J. Zhou, S. Liu, and B. Tu, "Time-dependent deformation mechanism for swelling soft-rock tunnels in coal mines and its mathematical deduction," International Journal of Geomechanics, vol. 20, no. 3, Article ID 04019186, 2020.

[3] Z. Zhou, W. Ma, S. Zhang, Y. Mu, and G. Li, "Experimental investigation of the path-dependent strength and deformation behaviours of frozen loess," Engineering Geology, vol. 265, Article ID 105449, 2020.

[4] S. Li, C. Wang, X. Xu, L. Shi, and N. Yin, "Experimental and statistical studies on the thermal properties of frozen clay in Qinghai-Tibet Plateau," Applied Clay Science, vol. 177, pp. 1-11, 2019.

[5] Z. Zhou, W. Ma, S. Zhang, Y. Mu, and G. Li, "Effect of freezethaw cycles in mechanical behaviors of frozen loess," Cold Regions Science and Technology, vol. 146, pp. 9-18, 2018.

[6] D. Ma, Q. Ma, Z. Yao, and K. Huang, "Static-dynamic coupling mechanical properties and constitutive model of artificial frozen silty clay under triaxial compression," Cold Regions Science and Technology, vol. 167, Article ID 102858, 2019.

[7] Y. Shen, Y. Wang, Y. Yang, Q. Sun, T. Luo, and H. Zhang, "Influence of surface roughness and hydrophilicity on 
bonding strength of concrete-rock interface," Construction and Building Materials, vol. 213, pp. 156-166, 2019.

[8] Y. Shen, H. Yang, J. Xi, Y. Yang, Y. Wang, and X. Wei, “A novel shearing fracture morphology method to assess the influence of freeze-thaw actions on concrete-granite interface," Cold Regions Science and Technology, vol. 169, Article ID 102900, 2020.

[9] S. Xie, H. Lin, Y. Wang et al., "A statistical damage constitutive model considering whole joint shear deformation," International Journal of Damage Mechanics, vol. 29, no. 6, pp. 988-1008, 2020.

[10] S. Xie, H. Lin, Y. Chen, R. Yong, W. Xiong, and S. Du, "A damage constitutive model for shear behavior of joints based on determination of the yield point," International Journal of Rock Mechanics and Mining Sciences, vol. 128, Article ID 104269, 2020.

[11] Y. F. Yang, G. Li, Z. Z. Liang, and C. A. Tang, "Numerical investigation on crack branching during collision for rock-like material," Theoretical and Applied Fracture Mechanics, vol. 76, pp. 35-49, 2015.

[12] J. Yu, X. Chen, H. Li, J.-w. Zhou, and Y.-y. Cai, "Effect of freeze-thaw cycles on mechanical properties and permeability of red sandstone under triaxial compression," Journal of Mountain Science, vol. 12, no. 1, pp. 218-231, 2015.

[13] D. Ma, Q. Ma, and P. Yuan, "SHPB tests and dynamic constitutive model of artificial frozen sandy clay under confining pressure and temperature state," Cold Regions Science and Technology, vol. 136, pp. 37-43, 2017.

[14] Z. Zhu, J. Jia, and F. Zhang, "A damage and elastic-viscoplastic constitutive model of frozen soil under uniaxial impact loading and its numerical implementation," Cold Regions Science and Technology, vol. 175, Article ID 103081, 2020.

[15] Q. Y. Ma, Frozen Soil Blasting and Drilling Test and its Application, Science Press, Beijing, China, 2007.

[16] D.-D. Ma, Q.-Y. Ma, Z.-M. Yao, P. Yuan, and R.-R. Zhang, "Dynamic mechanical properties and failure mode of artificial frozen silty clay subject to one-dimensional coupled static and dynamic loads," Advances in Civil Engineering, vol. 2019, Article ID 4160804, 9 pages, 2019.

[17] J. Yu, S.-j. Chen, X. Chen, Y.-z. Zhang, and Y.-y. Cai, "Experimental investigation on mechanical properties and permeability evolution of red sandstone after heat treatments," Journal of Zhejiang University-SCIENCE A, vol. 16, no. 9, pp. 749-759, 2015.

[18] J. Zhao, P. Zhang, X. Yang, and J. Qi, "On the uniaxial compression strength of frozen gravelly soils," Cold Regions Science and Technology, vol. 171, Article ID 102965, 2020.

[19] Q. Xie, Z. Zhu, and G. Kang, "A dynamic micromechanical constitutive model for frozen soil under impact loading," Acta Mechanica Solida Sinica, vol. 29, no. 1, pp. 13-21, 2016.

[20] Q.-Y. Ma, "Experimental analysis of dynamic mechanical properties for artificially frozen clay by the split Hopkinson pressure bar," Journal of Applied Mechanics and Technical Physics, vol. 51, no. 3, pp. 448-452, 2010.

[21] F. Zhang, Z. Zhu, T. Fu, and J. Jia, "Damage mechanism and dynamic constitutive model of frozen soil under uniaxial impact loading," Mechanics of Materials, vol. 140, Article ID 103217, 2020.

[22] T. Fu, Z. Zhu, D. Zhang, Z. Liu, and Q. Xie, "Research on damage viscoelastic dynamic constitutive model of frozen soil," Cold Regions Science and Technology, vol. 160, pp. 209-221, 2019.

[23] F.-Q. Gong, X.-F. Si, X.-B. Li, and S.-Y. Wang, "Dynamic triaxial compression tests on sandstone at high strain rates and low confining pressures with split Hopkinson pressure bar," International Journal of Rock Mechanics and Mining Sciences, vol. 113, pp. 211-219, 2019.

[24] F.-Q. Gong and G.-F. Zhao, "Dynamic indirect tensile strength of sandstone under different loading rates," Rock Mechanics and Rock Engineering, vol. 47, no. 6, pp. 2271-2278, 2014.

[25] W. Wang, S. Zhang, H. Li, S. Gong, and Z. Liu, "Analysis of the dynamic impact mechanical characteristics of prestressed saturated fractured coal and rock," Advances in Civil Engineering, vol. 2019, Article ID 5125923, 10 pages, 2019.

[26] Y. Wang, H. Zhang, H. Lin, Y. Zhao, and Y. Liu, "Fracture behaviour of central-flawed rock plate under uniaxial compression," Theoretical and Applied Fracture Mechanics, vol. 106, pp. 101-121, 2020.

[27] D. Li, Z. Han, Q. Zhu, Y. Zhang, and P. G. Ranjith, "Stress wave propagation and dynamic behavior of red sandstone with single bonded planar joint at various angles," International Journal of Rock Mechanics and Mining Sciences, vol. 117, pp. 162-170, 2019.

[28] Y. Bai, R. Shan, Y. Ju et al., "Experimental study on the strength, deformation and crack evolution behaviour of red sandstone samples containing two ice-filled fissures under triaxial compression," Cold Regions Science and Technology, vol. 174, Article ID 103061, 2020.

[29] W. Zhang, Q. Sun, and Y. Zhang, "Effects of pre-existing cracks and temperature on failure mode of granite from Eastern China," Journal of Structural Geology, vol. 126, pp. 330-337, 2019.

[30] S.-Q. Yang, P.-F. Yin, Y.-C. Zhang et al., "Failure behavior and crack evolution mechanism of a non-persistent jointed rock mass containing a circular hole," International Journal of Rock Mechanics and Mining Sciences, vol. 114, pp. 101-121, 2019.

[31] S. Y. Wang, S. W. Sloan, D. C. Sheng, S. Q. Yang, and C. A. Tang, "Numerical study of failure behaviour of precracked rock specimens under conventional triaxial compression," International Journal of Solids and Structures, vol. 51, no. 5, pp. 1132-1148, 2014.

[32] Y. Shen, Y. Wang, X. Wei, H. Jia, and R. Yan, "Investigation on meso-debonding process of the sandstone-concrete interface induced by freeze-thaw cycles using NMR technology," Construction and Building Materials, vol. 252, Article ID 118962, 2020.

[33] Z. Zhou, X. Cai, D. Ma et al., "Water saturation effects on dynamic fracture behavior of sandstone," International Journal of Rock Mechanics and Mining Sciences, vol. 114, pp. 46-61, 2019.

[34] M. Chen, H. Zhong, and M. Zhang, "Flexural fatigue behaviour of recycled tyre polymer fibre reinforced concrete," Cement and Concrete Composites, vol. 105, Article ID 103441, 2020.

[35] Q. Ma, D. Ma, and Z. Yao, "Influence of freeze-thaw cycles on dynamic compressive strength and energy distribution of soft rock specimen," Cold Regions Science and Technology, vol. 153, pp. 10-17, 2018.

[36] Z. Zhou, W. Ma, S. Zhang, C. Cai, Y. Mu, and G. Li, "Damage evolution and recrystallization enhancement of frozen loess," International Journal of Damage Mechanics, vol. 27, no. 8, pp. 1131-1155, 2018.

[37] Y. Mu, W. Ma, G. Li, Y. Mao, and Y. Liu, "Long-term thermal and settlement characteristics of air convection embankments with and without adjacent surface water ponding in permafrost regions," Engineering Geology, vol. 266, Article ID 105464, 2020.

[38] Q.-Y. Ma, D.-D. Ma, P. Yuan, and Z.-M. Yao, "Energy absorption characteristics of frozen soil based on SHPB test," Advances in Materials Science and Engineering, vol. 2018, Article ID 5378173, 9 pages, 2018. 